http://emaberto.inep.gov.br/index.php/emaberto/article/view/3262/pdf. Acesso em: 6 fev. 2018.

\title{
Referência
}

GARCIA, Adir Valdemar; YANNOULAS, Silvia Cristina. Educação, pobreza e desigualdade social. Revista Em Aberto, Brasília, v. 30, n. 99, p. 21-41, maio/ago. 2017. Disponível em:

<http://emaberto.inep.gov.br/index.php/emaberto/article/view/3262/pdf>. Acesso em: 6 fev. 2018. doi: http://dx.doi.org/10.24109/2176-6673.emaberto.30i99. 


\section{Educação, pobreza \\ e desigualdade social}

Adir Valdemar Garcia

Silvia Cristina Yannoulas

\section{Resumo}

Apresenta reflexões sobre a universalidade e a obrigatoriedade escolar na educação básica considerando as tensões, os conflitos e as contradições educacionais na ordem do capital. Reflete também sobre as possíveis alterações quanto à permanência das crianças na escola e à sua condição de pobreza decorrentes da condicionalidade estabelecida pelo Programa Bolsa Família (PBF), visto que a obrigatoriedade escolar já era uma questão constitucional anteriormente estabelecida. Conclui que a educação na ordem do capital não pode ser responsabilizada pela erradicação da pobreza, dado que essa é um problema estrutural, no entanto, é fundamental continuar lutando pela garantia de acesso, condições de permanência e qualidade. Conclui também que a condicionalidade imposta pelo PBF modificou, em certa medida, a condição educacional de alunos/as pobres, mas se constitui em um instrumento que fere a própria condição de sujeito de direito daqueles que se submetem a essa imposição.

Palavras-chave: condicionalidade; obrigatoriedade escolar; pobreza; política educacional; universalidade da educação básica. 


\section{Abstract \\ Education, poverty and social inequality}

This article reflects on the universality and compulsory attendance in primary education, in view of the tensions, conflicts and educational contradictions in capitalism. It also reflects on the possible changes regarding children's school attendance and their poverty conditions resulting from the conditionality established by the Programa Bolsa Família (PBF - The Family Grant Program), considering that compulsory education was already an established constitutional demand. The conclusion is that education, in capitalism, cannot be held accountable for eradicating poverty since this is a structural problem; however, it is essential to continue fighting to guarantee access, permanence conditions, and quality. It also concludes that the conditionality imposed by PBF has altered, to some extent, the educational condition of poor students; nevertheless it constitutes an instrument that infringes their condition as subjects of rights.

Keywords: conditionality; compulsory education; poverty; educational policy; universality of primary education.

\section{Introdução}

As reflexões sobre a educação na ordem social do capital ocorrem desde o estabelecimento dessa ordem. Aliás, a educação cumpre um papel fundamental no contexto social, considerando as perspectivas clássicas da análise social funcionalista, marxista e fenomenológica. Ainda que não haja coincidências em relação ao papel atribuído à educação por essas perspectivas clássicas, é evidente a importância atribuída a ela no que diz respeito à inovação e à reprodução da ordem social do capital (Garcia; Tumolo, 2009; Garcia, 2012).

\footnotetext{
Existe um debate quase permanente sobre o poder da educação para resolver os problemas da desigualdade social. Ora se espera tudo da educação, ora se coloca a educação como a fonte da eterna reprodução da mesma sociedade desigual. A educação formal pública é uma das demandas das sociedades modernas. No Brasil, a luta por uma educação pública de qualidade para todos é pleiteada por movimentos sociais e entendida como elemento fundamental de uma sociedade democrática e republicana. Contudo, o debate sobre a universalização da educação deve estar acompanhado de uma reflexão sobre o papel que o sistema educacional assume na realização de políticas sociais focalizadas, como a política de assistência social. (Yannoulas, 2013a, p. 17).
}

Ao propormos, no presente artigo de revisão, uma reflexão sobre universalidade, obrigatoriedade e condicionalidade escolar na educação básica considerando as tensões, os conflitos e as contradições educacionais na ordem do capital, precisamos explicitar, de modo mais específico, nossa compreensão quanto 
a essas noções, bem como expor que tensões, conflitos e contradições se estabelecem, com base na forma e no papel da educação nessa ordem social.

Nesse sentido, o artigo está organizado em duas seções: na primeira, trataremos dos conceitos de universalidade e obrigatoriedade; na segunda, problematizaremos o conceito de condicionalidade e as alterações quanto à permanência das crianças na escola decorrentes do Programa Bolsa Família (PBF). Em ambas, buscamos apresentar tensões, conflitos e contradições que se estabelecem no âmbito da política e da prática educacional. Para finalizar, apresentaremos algumas considerações que, longe de concluir a leitura realizada, pretendem abrir novos horizontes para pensar a questão da relação entre pobreza e educação.

As reflexões e conclusões aqui apresentadas se baseiam em artigos, livros e sites de instituições que tratam da temática abordada. Os/as autores/as foram escolhidos/as entre muitos/as que tratam do assunto e que respondem ao objetivo central aqui proposto. Fazer escolhas nesse sentido é sempre uma tarefa difícil.

\section{Universalidade e obrigatoriedade da educação: aspectos teóricos}

É importante refletir sobre esses conceitos, principalmente porque estão relacionados entre si e com a questão do direito à educação. Quando se fala em universalidade da educação, logo se pensa na significação de alcance da política educacional. Ou seja, uma política educacional universal é aquela devida a todos/as. Mas a universalização da educação enseja uma reflexão um pouco mais complexa, visto que, para além do alcance, está em jogo, principalmente, a qualidade e o papel da educação no contexto social. A condição de universalidade está sempre relacionada ao tipo de sujeito e de sociedade desejado.

Novelli (2012), analisando a educação na perspectiva hegeliana, apresenta, no resumo de seu texto, as seguintes questões: "Pode a educação não ter o alcance da universalidade? A universalidade é o aniquilamento do indivíduo? Pode o indivíduo ter sua identidade enquanto tal preservada no Estado?" (Novelli, 2012, p. 179). Segundo o autor, a compreensão de Hegel é que a educação universaliza o indivíduo quando o introduz na vida do Estado. É no âmbito do Estado que a subjetividade e a individualidade são conhecidas, preservadas e promovidas. Nesse caso, a educação precisa ser conduzida pelo Estado, que deve assumir sua organização e execução, mesmo que não diretamente, mas sempre sob sua supervisão: "Isso porque o Estado educa para a universalidade e não para a particularidade muito embora a particularidade não seja nem coibida nem abandonada à própria sorte" (Novelli, 2012, p. 181-182).

Segundo o autor, na perspectiva de Hegel, é "pela educação [que] o Estado introduz todos à sua vida" (Novelli, 2012, p. 182). Nesse sentido, a

vida não é dada pela primeira natureza como ser natural, mas somente pela participação na vida da razão. Não se trata de uma vida dada, mas de uma vida buscada, construída e compartilhada. Não se trata de uma vida determinante, mas determinada, ou seja, de uma vida que se quer de um certo modo. (Novelli, 2012, p. 182 - grifo nosso). 
Dessa forma, a educação no Estado coloca a criança e o jovem na condição de participantes do "universal", o que faz com que essa mesma educação funde a liberdade suprema por estabelecer-se como universalidade. Para Hegel,

\begin{abstract}
Em cada momento o Estado em gestação forma e conforma seus membros segundo seus interesses. Essa formação (Bildung) ${ }^{1}$ e conformação arregimentam os membros desejados e, na sua maior parte o "Estado" vigente tinha os componentes para si, porém não era um Estado para os mesmos. Isso porque a particularidade reinava sobre a universalidade nos grupos oligárquicos e privilegiados. A educação do e no Estado moderno forma e conforma para si porque forma e conforma em si cada um de seus momentos. Ele se sustenta sobre essa universalidade na qual as particularidades se reconhecem. (Novelli, 2012, p. 185 - grifo nosso).
\end{abstract}

Nessa perspectiva, "a educação formal é o momento privilegiado da formação do Estado e no Estado, pois o conteúdo, embora sendo sempre a vida universal do Estado, é explícito e especificamente o tratamento desse conteúdo na sua expressão histórica" (Novelli, 2012, p. 191). A educação formal constitui-se como "a formalização do pensar do Estado e do Estado que aí se pensa. A educação de indivíduos no Estado é a educação individual do Estado que confronta a particularidade e singulariza a universalidade" (Novelli, 2012, p. 191).

De acordo com Ramos (1993), para Hegel o indivíduo efetiva-se, realmente, no Estado, cabendo à sociedade civil burguesa realizar a mediação pacífica entre este e aquele, ao passo que, para Marx,

\begin{abstract}
a relação entre a liberdade subjetiva do indivíduo e a universalidade do Estado aparece como sendo não conflituosa porque a ênfase dada ao Estado por Hegel revela-se como resolução meramente política para as contradições decorrentes da própria lógica das relações de produção da sociedade burguesa, a qual, necessitando ocultar os seus antagonismos reais, traveste-se numa idealização política representada pela universalização do poder positivo do Estado. Marx compreende a sociedade (capitalista) travejada por "universalidade" que porfiam (sic) em fazer do homem e da sua liberdade um momento "pacífico" na integração com o Estado. (Ramos, 1993, p. 57).
\end{abstract}

Por isso, em razão de não acatar a positividade do Estado na legitimação do seu poder, Marx faz uma crítica contundente à caracterização desse Estado como instrumento de sustentação da sociedade burguesa. Sob o manto da universalidade, realiza e legitima a exploração de uma classe pela outra, como denuncia a obra Manifesto do Partido Comunista, na qual Marx e Engels (2002) deixam claro o papel central do Estado na defesa dos interesses da burguesia.

Essas perspectivas diferenciadas demonstram uma disputa no âmbito das explicações da realidade social. Se, por um lado, a universalidade é considerada expressão do interesse de todos a partir do Estado, por outro, é vista como forma ideológica destinada a ocultar interesses particulares de determinada classe social, sendo o Estado o instrumento utilizado para tal. A educação, tanto em sua expressão geral como em sua forma escolar, compõe a ordem social e, portanto, reflete as tensões, os conflitos e as contradições dessa ordem social.

\footnotetext{
${ }^{1}$ No idioma alemão existem dois conceitos para educação: Bildung (formação, cultivo) e Erzihung (educação formal) O primeiro termo enfatiza o resultado da formação, a cultura; e o segundo, o processo educativo, uma formação mediada pela teoria educacional. Essa diferenciação foi amplamente debatida por Hegel.
} 
Segundo a perspectiva marxista de Mészáros (1993), para o bom funcionamento do metabolismo social, numa sociedade eivada de contradições, é o papel ativo da estrutura legal e política, a partir de sua autonomia relativa da base material, que resulta necessariamente numa autonomia relativa das ideias e formas da consciência social com relação a essa superestrutura legal e política. Nesse caso, em sociedades de classe, o "interesse de todos" seria a expressão do funcionamento tranquilo da ordem social, no qual os interesses dos setores dominantes não correriam riscos. Portanto, "'o interesse de todos' é um conceito ideológico vazio, cuja função é a legitimação e a perpetuação do sistema de dominação dado" (Mészáros, 1993, p. 214).

Com relação à educação, o que vemos estabelecido é o predomínio da perspectiva funcionalista em detrimento das perspectivas críticas, mesmo que essas, em termos discursivos, tenham maior apelo. Durkheim (2011) inicia a presente reflexão, por entendermos que suas análises e proposições sobre e para a educação representam, efetivamente, as bases para o desenvolvimento da educação na ordem do capital. Não sem motivo era também sua preocupação com a educação moral. Isso não significa compreendermos que tal perspectiva tenha se estabelecido sem resistências ou, efetivamente, da forma como se apresenta.

Ao refletir sobre o significado da educação e sua importância para o funcionamento da sociedade, Durkheim (2011, p.48) afirma que a educação, a cada momento histórico, impõe-se aos indivíduos "com uma força, geralmente irresistível. Não adianta crer que podemos educar nossos filhos como quisermos. Há costumes aos quais somos obrigados a nos conformar; se os transgredirmos demais, eles acabam se vingando dos nossos filhos".

Da mesma forma, segundo esse autor, é necessário entender que a educação varia de acordo com o espaço e a classe social. Nesse caso, a do campo não é igual a da cidade e a do burguês não é igual a do operário. Mas a educação não deveria depender do acaso de se ter nascido aqui ou lá, em uma classe ou em outra. Mesmo que a consciência moral justifique essa posição, a educação não poderia ser mais uniforme, pois a diversidade moral das profissões exigiria grande diversidade pedagógica. Uma educação homogênea e igualitária só teria sido possível no seio das sociedades pré-históricas, em que não existia diferenciação alguma. A educação sempre repousa sobre uma base comum, como declara Durkheim, diferenciando-se posteriormente.

Durkheim defendia que a educação não deveria ficar à mercê das arbitrárias vontades individuais. Se ela é uma função essencialmente social, o Estado tem de interessar-se por ela. Isso não significava uma defesa de que o Estado devesse monopolizar o ensino. Para ele, o fato de a sociedade, de acordo com as suas necessidades, modelar os indivíduos, pode dar a entender que eles sofrem uma insuportável tirania. Porém, os indivíduos têm interesse nessa submissão, pois o ser que é edificado a partir da ação coletiva por meio da educação representa o que há de melhor em cada um, ou seja, o que há de propriamente humano em cada um. 
Partindo do fato de que a sociedade determina o indivíduo, bem como a aceitabilidade da organização social em classes e da ideia, defendida por ela, de que a educação tem que ser diferenciada, Dukheim também defendia a universalidade, porém, de acordo com Groppo (2007, p.3), criticava as compreensões liberais de educação que postulavam a existência de uma educação ideal universal, entendida "como um desenvolvimento em abstrato de todas as faculdades individuais", por desvincular a relação entre o desenvolvimento individual e a sociedade. Nesse caso, o objetivo da educação tornava-se livre arbítrio individual.

A tradição funcionalista, representada aqui por Durkheim, ocupa uma posição destacada no campo da análise educacional e das relações da educação com a estrutura social, e foi muito criticada por seus pressupostos conservadores, ignorando o conflito, a contradição, a luta e a mudança social. A educação não é percebida como um fator de conflito ou de superação de estruturas sociais existentes, mas sim como necessário conhecimento prático para manter o funcionamento de uma sociedade dada (Freitag, 1984).

A universalidade, a partir da perspectiva durkheimiana e congêneres, cumpre o papel de justificar e manter uma dada ordem social e, nesse caso, é clara a defesa de uma sociedade de classes. Porém, como dito anteriormente, esta não é a única visão a respeito da universalidade, visto que não há apenas uma explicação da realidade social. Saviani e Duarte (2010, p. 422-423), por exemplo, afirmam que

a análise do aspecto intelectual, isto é, da consciência, revela que o homem não se mantém preso às suas condições situacionais e pessoais. Ele é capaz de transcender a situação, assim como as opções e os pontos de vista pessoais, para colocar-se na perspectiva universal, entrando em comunicação com os outros e reconhecendo suas condições situacionais, assim como suas opções e seus próprios pontos de vista.

Nesse caso, a educação apresenta-se "como uma comunicação entre pessoas livres em graus diferentes de maturação humana. Nessa formulação, o valor da educação expressa-se como promoção do homem" (Saviani; Duarte, 2010, p. 423). Depreende-se daí que a educação coincide com o processo de formação humana. No entanto, é o trabalho que possibilita ao ser humano incorporar a natureza ao campo social, de forma histórica e universal. Ao fazer uma análise das contribuições da filosofia para a educação, Saviani (1990, p. 8) diz que "a educação não é outra coisa senão o processo através do qual se constitui em cada indivíduo a universalidade própria da espécie humana".

Segundo Severino (2006), a cultura ocidental sempre tratou a educação como processo de formação humana, significando a própria humanização do ser humano. Nesse sentido, o homem "sempre foi concebido como um ente que não nasce pronto, que tem necessidade de cuidar de si mesmo como que buscando um estágio de maior humanidade, uma condição de maior perfeição em seu modo de ser humano" (Severino, 2006, p. 621). Nesse caso, "a educação não é apenas um processo institucional e instrucional, seu lado visível, mas fundamentalmente um investimento formativo do humano, seja na particularidade da relação pedagógica pessoal, seja no âmbito da relação social coletiva" (Severino, 2006, p. 621 - grifo do autor). 
Ao referir-se ao que chamou de "situação degradada do momento históricosocial que atravessamos", Severino (2006, p. 621) destaca que o desafio da formação humana torna-se contingente. Para ele, ao falarmos de educação para além de processos de qualificação técnica, tratamos da formação de uma personalidade integral, denominada Bildung.

A universalidade, na perspectiva de sociabilidade defendida por esses autores, está vinculada à defesa de uma ordem social diferente daquela apresentada por Durkheim. Considerando esse outro sentido dado à busca da universalidade, retomamos alguns elementos da perspectiva de educação em Marx. Segundo Ferreira Jr. e Bittar (2008), a educação não foi o tema central de Marx e Engels, mas aparece nas suas preocupações sobre a construção do homem plenamente desenvolvido em suas potencialidades físicas e espirituais, não subjugado ao domínio do capital.

Segundo os autores, na teoria marxista, a perspectiva humanista da educação manifesta-se em dois momentos distintos, mas dialeticamente interligados: a) quando é feita a crítica da alienação produzida pelo processo educativo inerente a uma sociedade fundada no primado da propriedade privada dos meios de produção, que resulta na mutilação do homem; b) quando é proposta a possibilidade da omnilateralidade humana no âmbito da sociedade revolucionada, baseada em outros pressupostos econômicos, sociais, políticos e culturais. Nesse sentido, os princípios que guiam a proposição de educação de Marx são: a) o papel central e dialético do trabalho; b) a ideia de homem omnilateral (na qual se harmoniza "tempo de trabalho" e "tempo livre").

Se Marx não desenvolveu uma reflexão profunda e detalhada a respeito da educação, deixou claro seu papel no âmbito de uma sociedade de classe. Não sem motivo, defendia a necessidade de lutar por uma educação pública e gratuita para todas as crianças, com a abolição do trabalho dessas nas fábricas, como acontecia à época. Isto porque Marx via a estreita relação entre educação e produção da vida material, não podendo a educação estar desvinculada dos processos de produção. Por isso, na Crítica ao Programa de Gotha (1875), Marx refere-se à necessidade de, no mínimo, ser exigida a oferta de escolas técnicas (Ferreira Jr.; Bittar, 2008). Nesse mesmo texto, Marx também se posiciona contrário a uma "educação popular a cargo do Estado". Ao Estado caberia o estabelecimento de uma lei geral, bem como a garantia dos recursos materiais e humanos, mas não o papel de educador do povo. Ao contrário, a educação não poderia sofrer influência por parte do Governo e da Igreja (Ferreira Jr.; Bittar, 2008).

Deve ficar claro que, para o marxismo, a omnilateralidade somente pode realizar-se no âmbito de uma sociedade autorregulada do ponto de vista da produção, organização e distribuição dos objetos necessários para garantir a base material e espiritual do homem. Portanto, não há que esperar que ela ou, principalmente, que a partir dela se construa uma nova ordem social. A educação pode constituir-se em uma tática, mas não é a estratégia política em si. Como dito anteriormente, não encontramos em Marx, ou nos trabalhos dele com Engels, análise mais robusta e detalhada da educação. Para além dos textos que já fazem um trabalho de síntese do tema da educação nesses autores, sugerimos a leitura dos Textos sobre educação e ensino (Marx; Engels, 2011). 
Feita essa reflexão a respeito do caráter que a defesa da universalidade adquire, podemos debruçar-nos sobre a compreensão de universalidade como oferta, ou seja, universalização do atendimento. Essa perspectiva está intimamente relacionada com a instituição do direito à educação e do dever do Estado em garanti-la para todos, bem como com a instituição da obrigatoriedade. Logicamente, não pode ser dissociada do sentido dado ao seu papel.

Segundo Horta (1998), a proposta de ensino como direito de todos e como dever do Estado apareceu no século 18, sendo a Prússia, em 1763, o primeiro país a estabelecer a instrução primária obrigatória. Inicialmente a universalidade e a obrigatoriedade escolar estiveram relacionadas com o acesso direto dos fiéis aos textos religiosos no contexto protestante, e demandou o estabelecimento de uma formação docente sistemática e regulada:

\begin{abstract}
Hacia finales del siglo XVII surgió la preocupación por la formación docente en los estados territoriales del ámbito germánico. Se inauguraron en diferentes ciudades y vinculados a diferentes tipos de instituciones (escuelas primarias, orfelinatos, etc.) los seminarios de formación de maestros (Lehrerseminaren), basicamente a cargo de teólogos. Hacia mediados del siglo XVIII surgió y se expandió en el contexto del Império Austro-Húngaro la escuela normal (Normalschule), también a cargo de teólogos (Engelbrecht; 1984 y O’Brien; 1970). Con la Revolución, se incorporó en Francia el modelo institucional de las escuelas normales (écoles normales), pero en un contexto básicamente laico. (Yannoulas, 1992, p. 511).
\end{abstract}

A escola primária gratuita e laica estabeleceu-se na França na Terceira República (1878-1882), mesma época em que ocorreu na Inglaterra e no País de Gales. Com a Declaração Universal dos Direitos Humanos de 1948, a educação passou a ser um direito de todas as pessoas, devendo ser gratuita ao menos na instrução elementar e fundamental, sendo obrigatória a elementar.

Cury e Ferreira (2010) afirmam que a obrigatoriedade do ensino sempre foi tema controverso, visto que necessidades sociais, econômicas e políticas impõem à população um mínimo de conhecimento obrigatório, o que implica, ao mesmo tempo, a imposição de limites à liberdade individual. Por outro lado, asseveram os autores:

a educação passou a ser reconhecida como um direito fundamental (direito humano) advindo da positivação deste direito, com implicação na questão da obrigatoriedade do ensino. O acesso ao ensino, até como antídoto à ignorância, torna-se uma exigência para cuja efetivação os dispositivos legais positivados são um instrumento para assegurar sua oferta. Evidentemente, o acesso a etapas de ensino é condição de possibilidade para a exigência da qualidade do serviço. (Cury; Ferreira, 2010, p. 125).

Horta (1998), citando Hubermann, também chama a atenção para o fato de, diferentemente de outros direitos sociais, a educação ser obrigatória. Com relação ao usufruto de todos os direitos, a população pode optar, mas, quanto à educação, não: "neste caso, o direito é, ao mesmo tempo, uma obrigação. Assim, a inclusão do direito à educação entre os direitos sociais se apresenta ao mesmo tempo como uma conquista e uma concessão, um direito e uma obrigação" (Horta, 1998, p. 10). Por isso, mesmo que o direito e a obrigatoriedade tenham surgido em momentos diferentes, devem ser estudados conjuntamente em razão de estarem intimamente relacionados. Afirma ainda que, na realidade brasileira, durante muito tempo, "ao 
direito de educar por parte do Estado correspondeu a obrigatoriedade escolar como imposição ao indivíduo. Só muito recentemente, ao direito à educação, por parte do indivíduo, correspondeu a obrigatoriedade de oferecer a educação, por parte do Estado" (Horta,1998, p. 10).

Apresentamos uma síntese do percurso da obrigatoriedade da educação no Brasil feita por Cury e Ferreira (2010) a partir das constituições federais. Na Constituição Imperial de 1824, faz-se referência à instrução pública como um direito, mas somente daqueles considerados cidadãos, os homens e mulheres escravizados estavam excluídos do acesso ao ensino oficial. Nessa constituição, ainda não se colocava a questão da obrigatoriedade escolar. Na Constituição de 1891, a gratuidade e a obrigatoriedade não foram estabelecidas. O ensino primário ficou a cargo dos estados e apenas os estados de São Paulo, Santa Catarina, Mato Grosso e Minas Gerais trataram da obrigatoriedade do ensino primário. Já na Constituição de 1934, tomando como referência o Manifesto dos Pioneiros de 1932, a educação ganha capítulo próprio e prevê a necessidade de um plano nacional de educação. Esse plano deveria contemplar o ensino primário integral gratuito e de frequência obrigatória, extensivo aos adultos.

A Constituição Federal de 1937 restringe os deveres do Estado para com a manutenção do ensino, o que implica a perda de conquistas anteriores. Essa constituição aponta a responsabilidade dos pais quanto ao dever da educação, não implicando dever do Estado. A Constituição Federal de 1946 avançou novamente no sentido da adoção do princípio do ensino primário obrigatório. Nas constituições de 1967 e 1969, foi estabelecida a obrigatoriedade do ensino primário para todos, dos 7 aos 14 anos, e a gratuidade nos estabelecimentos oficiais. Mesmo assim, a educação não foi garantida como um direito público subjetivo em razão da ausência de recursos materiais e humanos. Na Constituição de 1988, temos um avanço significativo, posto que essa estabelece a educação como um direito social fundamental para a cidadania e também traz um capítulo próprio sobre a educação, retomando a obrigatoriedade do ensino e instituindo-a como direito público subjetivo. Como observam Cury e Ferreira (2010, p. 135),

\footnotetext{
na evolução constitucional do direito à educação, as normas reguladoras deixaram de possuir um caráter programático para ganhar efetividade como direito público subjetivo. Deixaram de ser meros enunciados contemplativos para se transformarem em diretrizes a serem seguidas pelo Poder Público, sob pena de responsabilização.
}

Os autores chamam atenção para o fato de que da obrigatoriedade da oferta da educação básica por parte do Estado decorrem contrapartidas que devem ser cumpridas por alunos/as e seus/suas responsáveis, a exemplo da matrícula e da frequência. Os autores apresentam o Estatuto da Criança e do Adolescente, de 1990, como instrumento de controle/acompanhamento e punição, quando as obrigações de matrícula e frequência escolar são descumpridas por alunos/as e por responsáveis.

Cury e Ferreira (2010) ainda destacam, como faceta dessa discussão que envolve direito e obrigatoriedade, o atendimento incondicional a todos/as aqueles/ as abarcados pela lei, com o nível de qualidade socialmente esperado e legalmente 
definido. Nesse sentido, não basta a oferta, mas seu efetivo atendimento. Fazendo referência ao ensino fundamental, os autores dizem que, em termos de matrícula, este está praticamente universalizado.

\begin{abstract}
Mas isto não significa que esta etapa da educação está sendo universalizada, pois uma situação é a criança estar matriculada no ensino fundamental e outra é a criança efetivamente cursar o ensino fundamental. Universalizamos a matrícula, mas não o ensino. O insucesso escolar em face da repetência e da evasão é bastante frequente. (Cury; Ferreira, 2010, p. 140).
\end{abstract}

Fica claro o quanto o processo de estabelecimento da universalidade e da obrigatoriedade, com relação à educação, implica conflitos e tensões, não só no que diz respeito aos processos sociais mais gerais, mas também aos processos pedagógicos formais que se desenvolvem no cotidiano escolar. Afinal, a universalidade e a obrigatoriedade não podem ser desvinculadas da oferta e da qualidade da educação, tampouco dos modelos educativos e da forma da organização escolar.

Feitos esses apontamentos a respeito da universalidade e da obrigatoriedade, passamos a refletir sobre outro conceito contemporâneo relacionado a esses: a condicionalidade.

\title{
Condicionalidade, permanência das crianças na escola e desafios para a organização escolar
}

Para iniciar essa reflexão sobre a condicionalidade escolar estabelecida no Brasil e relacionada ao Programa Bolsa Família (PBF), partimos da discussão sobre pobreza não como um problema puramente técnico ou explicado pelas condições individuais de cada sujeito, mas como um problema de caráter estrutural, socialmente constituído e não "natural". Como tal, entendemos que não se trata de um problema que possa ser resolvido no interior da própria ordem social que o gera.

Os dados sobre a pobreza podem até ter demonstrado uma diminuição no passado recente, mas estamos longe da possibilidade de erradicá-la, muito menos de seu efetivo controle, como se pode verificar pela consideração do que ocorre em momentos mais agudos de crise, como os atuais.

Segundo o relatório da Oxfam² (2014), uma em cada seis pessoas no mundo sofre os efeitos perniciosos da pobreza, e $50 \%$ da riqueza mundial está com $1 \%$ da população; além disso, sete em cada dez pessoas vivem em países onde a desigualdade aumentou nos últimos 30 anos.

De acordo com o relatório Panorama Social da América Latina, publicado pela Comissão Econômica para a América Latina e o Caribe (Cepal), em 2014, a taxa de pobreza no continente, em 2013 , foi de $28,1 \%$ da população, enquanto a pobreza extrema alcançou $11,7 \%$. Os percentuais correspondem a 165 milhões de pessoas em situação de pobreza, das quais 69 milhões correspondem àquelas em situação de pobreza extrema (Cepal, 2014).

Especificamente no caso do Brasil, em 2009, segundo o Instituto de Pesquisa Econômica Aplicada (Ipea), 40.066.020 pessoas eram pobres e 13.597.606 eram

\footnotetext{
${ }^{2}$ Oxfam é uma confederação de 20 organizações não governamentais que atua em 90 países para combater as injustiças causadoras da pobreza.
} 
consideradas extremamente pobres. Em 2014, segundo dados desse mesmo Instituto, o número de pobres no Brasil era de 25.888 .565 pessoas e o de extremamente pobres era de 8.191.008 pessoas (Ipea, 2017a, 2017b.).

Como posto anteriormente, o reconhecimento de que a educação é fundamental para retirar as pessoas da condição de pobreza está nas leis, nos planejamentos governamentais, no discurso político e intelectual, no discurso de senso comum. Não sem motivo, constitui-se em uma condicionalidade para o recebimento de um recurso que, para muitos, significa a própria possibilidade de viver. Entendemos que a educação não tem esse "poder", mas defendemos sua importância nos processos de luta e transformação social.

De todo modo, o entendimento sobre a pobreza aqui apresentado, ao ser relacionado à política educacional, permite tencionar a suposta universalidade da educação básica, uma vez que foi garantido o acesso da população pobre à escola, sem, no entanto, serem oferecidas as condições necessárias para sua permanência e aprendizagem com qualidade. Afinal, se a educação é fundamental para a saída da condição de pobreza, como afirma o discurso majoritário, a matrícula, por si só, não é suficiente.

Ao tratar sobre a pobreza e o público estudantil, Duarte (2012) indicou que 44\% da população escolar no ensino fundamental público no Brasil estava em situação de pobreza em 2009. O critério utilizado por essa autora para identificar a população em situação de pobreza foi o de considerar o número de estudantes das escolas públicas, beneficiários do PBF. No caso do estado de Alagoas, 73\% dos estudantes eram beneficiários desse programa. Na região Nordeste, 67\% estavam nessa situação. Esses dados indicam que, ao tratarmos da relação entre educação e pobreza, não estamos falando de minorias. Estamos dizendo que grande parte da população inserida na escola pública brasileira traz consigo as demarcações da condição social centrada no recorte de renda (ser beneficiário de programa de transferência de renda).

Apresentamos também alguns dados da relação entre pobreza e educação básica no Brasil após o advento do PBF, com o objetivo de dimensionar alguns dos potenciais impactos educacionais decorrentes da implantação do Programa. De acordo com o relatório de 2014 da Secretaria de Educação Continuada, Alfabetização, Diversidade e Inclusão (Secadi) do Ministério da Educação (MEC), que analisa o trabalho realizado no acompanhamento do PBF no período 2005-2014, 17 milhões de alunos/as eram beneficiários/as desse programa em 2014, o que representava 1/3 do total de matrículas da educação básica. Havia 40 mil profissionais envolvidos com o acompanhamento da frequência escolar dos beneficiários, considerando as esferas federal, estadual e municipal. O percentual de 80\% (153.000) das escolas do País contava com alunos/as beneficiários/as do PBF. Com relação ao aproveitamento, os/as alunos/as de ensino médio beneficiários/as do PBF tinham maior aprovação que aqueles não beneficiários/as (os piores rendimentos entre os/as alunos/as beneficiários/as do PBF estavam nas séries iniciais). Dados preliminares relativos ao ano de 2015, ainda não divulgados pela Secadi, apresentados aos coordenadores estaduais do PBF na educação em reuniões técnicas realizadas em Brasília em 2016, 
apontam para um aumento desses números, de modo que a perspectiva era de que, naquele ano, 53\% dos alunos matriculados na educação básica eram beneficiários do PBF.

O ingresso de pessoas em situação de pobreza na escola pública ocorreu nos parâmetros e no formato escolar que, historicamente, foi predefinido e predeterminado pela organização escolar construída para minorias privilegiadas. Quais seriam as transformações escolares necessárias em termos de organização escolar, formação dos trabalhadores da educação, curriculum, sistema de avaliação, projetos políticospedagógicos, entre outros aspectos importantes, dada a quantidade de estudantes das escolas públicas que se encontram em situação de pobreza? A condicionalidade está implicando mudanças efetivas nesses aspectos?

Se as discussões sobre direito e obrigatoriedade podem ser, digamos, acaloradas, os motivos para dissensos parecem aumentar quando a condicionalidade entra em cena. Zimmermann (2006) diz que o PBF é um dos principais instrumentos de combate à fome e de garantia do direito humano à alimentação no Brasil. O autor cita o Pacto Internacional de Direitos Econômicos, Sociais e Culturais, de $1966,{ }^{3}$ que reconhece o direito fundamental de toda pessoa estar livre da fome, obrigando os Estados signatários a adotarem medidas e a concretizarem programas para atingir esse fim. O direito à alimentação é individual e deve ser garantido de maneira universal e incondicional a todo ser humano. O autor destaca que o PBF, ao impor condicionalidades a um direito, acaba ferindo o pressuposto de que a condição de pessoa deve ser o requisito único para a titularidade de direitos. Segundo o autor,

O Estado não deve punir e, em hipótese alguma, excluir os beneficiários do
Programa, quando do não cumprimento das condicionalidades estabelecidas e/ou
impostas. Dever-se-ia responsabilizar os municípios, estados e outros organismos
governamentais pelo não cumprimento de sua obrigação em garantir o acesso aos
direitos atualmente impostos com condicionalidades. (Zimmermann, 2006, p. 153).

Pires (2013) afirma que a proposição de condicionalidade de frequência escolar para recebimento de benefícios de programas de transferência de renda surge, no Brasil, a partir de contribuições do economista José Márcio de Camargo, no início da década de 1990. A discussão nasceu com base nas propostas iniciais dos programas de garantia de renda mínima elaboradas por alguns governos municipais nos anos de 1990. Segundo Pires, na análise de Camargo, as crianças pobres abandonam a escola para trabalharem em atividades pouco qualificadas e sem perspectivas profissionais, mesmo que, com essa atitude, contribuam para a renda familiar, serão os pobres do futuro. Por isso, seria necessário aumentar a renda familiar para que os filhos sejam mantidos na escola, promovendo a quebra do elo entre a pobreza do presente e a do futuro. Aqui se verifica, muito claramente, como é tratada a relação educação/pobreza, como especificado anteriormente.

Ribeiro (1991) também tratou da questão da evasão escolar. Para esse autor, um dos graves problemas enfrentados na educação brasileira, considerando os dados

\footnotetext{
3 Em vigor no Brasil com a promulgação do Decreto n 591/1992.
} 
de Pesquisa Nacional por Amostra de Domicílios (Pnad) da década de 1980, era o abandono escolar em função do excesso de repetências acumuladas pelos alunos. Esse era, na sua visão, o maior entrave para a universalização da educação básica. Nesse sentido, sua constatação acaba colidindo, em certa medida, com o que diz Camargo, citado por Pires (2013). "Em certa medida", pois Ribeiro (1991) não desconsidera a situação diferenciada daqueles que pertencem às camadas mais empobrecidas da sociedade brasileira, esses reprovam mais e abandonam mais. Mesmo que sua conclusão seja que a repetência está mais ligada à formação dos professores e à organização escolar, não seria possível deduzir desse seu estudo que a repetência não tenha como uma de suas causas a necessidade de sustento. Na mesma linha de Ribeiro, Klein (2006) também aponta a repetência como um grave problema relacionado ao abandono escolar. O autor destaca melhorias no quadro brasileiro considerando a década de 1990 e os primeiros anos de 2000, atentando para uma preocupação maior com a qualidade do ensino. Nos termos desse artigo, cabe destacar que o autor apresenta análises do Sistema de Avaliação da Educação Básica (Saeb) 2003 que revelam associações positivas entre desempenho e índice socioeconômico. Nesse caso, um nível socioeconômico mais alto implica maior desempenho, porém, ele diz que políticas públicas de educação não implicam alteração da variável econômica em curto prazo. Contudo, é esperado que, a médio e longo prazo, uma melhora da qualidade de ensino contribua para elevar o nível socioeconômico da população. É interessante destacar que o contrário também é verdadeiro, ou seja, a melhoria no nível socioeconômico implica melhoria nos níveis de educação. No entanto, quando Klein (2006) apresenta metas para a melhoria da educação, entre elas não se encontra a necessidade de políticas voltadas para a ampliação do poder econômico das famílias.

Segundo Teles e Stein (2013), a Organização das Nações Unidas (ONU), em 2000, aprovou a Declaração do Milênio, com base em valores como a liberdade, a igualdade, a solidariedade, a tolerância, o respeito à natureza e a responsabilidade comum. Os dirigentes de 189 países signatários assumiram o compromisso de envidar todos os esforços para tirar da pobreza aqueles colocados nessa condição. Entre os compromissos assumidos, destacamos os dois mais diretamente afetos a este trabalho: a erradicação da pobreza extrema e da fome e a universalização do ensino primário.

Para o alcance desses objetivos, foram propostos os Programas de Transferência Monetária Condicionada (PTMCs), caracterizados pela transferência monetária às famílias em situação de pobreza ou extrema pobreza, com um ou mais filhos em idade escolar. Essa transferência deveria estar condicionada a "contraprestações" ou "corresponsabilidades" voltadas à melhoria de capital humano dos filhos. Compreendia-se que esses programas eram potencialmente capazes de reduzir a desigualdade, ajudando as famílias a romperem o "círculo vicioso da pobreza", evitando que essa condição se transmitisse de uma geração a outra. O foco seria incrementar a capacidade de gerar renda no futuro. Essa proposição segue a mesma perspectiva de José Márcio de Camargo, destacada por Pires (2013). 
Os mencionados autores identificaram alguns argumentos em favor da condicionalidade. Nesse caso, a contrapartida seria importante porque:

1) as famílias pobres não têm condições de decidir sobre a importância de investimentos em saúde e em educação dos filhos;

2) o investimento privado das famílias em capital humano é muito baixo, o que provoca um atraso para toda a sociedade brasileira;

3) a distribuição de renda deve estar associada ao bom comportamento dos pobres que a mereça;

4) as famílias pobres ficariam mais responsáveis;

5) promove a pressão por aumento na oferta e na demanda por serviços públicos. (Teles; Stein, 2013, p. 195).

Como contraponto, apresentam a posição de Suplicy (2006), que entende que a transferência de renda incondicional apresenta as seguintes vantagens:

1) dissolve a burocracia utilizada na fiscalização das famílias;

2) elimina o sentimento de estigma e humilhação das famílias que são obrigadas a comprovar os critérios de elegibilidade para ter acesso ao programa;

3) elimina a possibilidade da armadilha da pobreza e do desemprego, pois a elevação da renda familiar per capita, mediante o acesso ao trabalho, não suspende ou extingue o benefício;

4) proporciona o sentimento de liberdade e dignidade, por não existir a preocupação de faltar o recurso no mês seguinte, pois a renda é um direito inalienável e de cidadania;

5) estimula o pleno emprego por meio do aumento da demanda por bens e serviços que impulsionaria o crescimento da economia e do emprego. (Teles; Stein, 2013, p. 196).

Pereira e Stein (2010), por sua vez, criticam as condicionalidades ou contrapartidas, visto que sua imposição faz parecer que o beneficiário tenha cometido alguma falta pessoal. Nessa compreensão, aquilo que é um problema social acaba transformando-se em um problema pessoal ou individual, que demanda ajuda pela qual é devido um retorno. Não se discute o direito em si. Teles e Stein (2013) atentam para o fato de a condicionalidade escolar estar vinculada à frequência escolar, o que faz com que a discussão sobre o direito à educação no contexto do PBF não avance na concepção de educação e na reflexão de outros graves problemas da educação brasileira, tais como a evasão escolar, a repetência, a qualidade do ensino, a formação e a valorização dos professores.

O que se percebe é que há uma preocupação no que tange ao aumento do número de anos de estudo, e, nesse caso, a condicionalidade acaba por responder positivamente. Levemos em consideração que o atual Plano Nacional de Educação (PNE), especificamente a Meta 8, propõe

elevar a escolaridade média da população de 18 (dezoito) a 29 (vinte e nove) anos, de modo a alcançar, no mínimo, 12 (doze) anos de estudo no último ano de vigência deste Plano, para as populações do campo, da região de menor escolaridade no País e dos $25 \%$ (vinte e cinco por cento) mais pobres, e igualar a escolaridade média entre negros e não negros declarados à Fundação Instituto Brasileiro de Geografia e Estatística - IBGE. (Brasil. Lei no 13.005, 2014). 
A inclusão dessa meta indica que a proposta é atingir a universalização da educação básica - o PNE também trata da qualidade da educação em sua Meta 7. No entanto, as medidas para a garantia da qualidade implicam forte investimento em infraestrutura das escolas, recursos pedagógicos, formação de professores e garantia de carreira digna para estes. Historicamente, no Brasil, as medidas relativas à qualidade da educação compõem o discurso legal e político, sem resultados concretos. E há que se considerar que os mais atingidos pela baixa qualidade da educação são, especialmente, as populações historicamente excluídas. A promulgação da Emenda Constitucional 95, de 2016, que limita por vinte anos os gastos públicos, implicará maiores problemas para a educação, significando que é possível que a tão desejada qualidade esteja cada vez mais distante e que muitas das propostas do PNE tornem-se "letra morta".

O aumento dos anos da educação obrigatória e da oferta de vagas é necessário, porém não suficiente. Não adianta aumentar os anos de escolaridade dos 25\% mais pobres sem implementar ações necessárias e específicas para extinguir as razões que levaram à exclusão de grupos significativos da população brasileira. Como dito anteriormente, não entendemos que a educação dê conta dessa tarefa, da mesma forma que questionamos as alternativas postas dentro da própria ordem do capital. No entanto, é necessário continuar lutando por políticas capazes de amenizar o histórico de desigualdade.

De qualquer modo, é necessário afirmar a importância de programas como o Bolsa Família. Mesmo que se concorde que a maior preocupação governamental esteja vinculada ao aumento do número de anos de estudo, desvinculada, em grande medida, da garantia da qualidade da educação, estudos mostram que a condicionalidade, apesar de todas as críticas que se possa fazer, resulta em alguns aspectos positivos.

Conforme Simões (2013), em entrevista publicada no Portal Brasil, os resultados de sua tese, defendida na Universidade de Sussex, Inglaterra, mostraram que o PBF ataca, diretamente, fatores que interferem no resultado da aprendizagem, a exemplo da frequência, visto que o aluno que vai à aula tem maiores chances de ter melhor desempenho. A exigência da presença também reduz a chance de envolvimento da criança e do jovem com o trabalho, remunerado ou não. O autor também destaca que o programa favorece o ingresso na escola na idade certa, além de garantir que essas crianças estejam alimentadas, menos sujeitas a doenças, o que também possibilita melhor desempenho. A própria família, à medida que tem maior segurança econômica, reduz o nível de estresse, possibilitando um maior bem-estar psicológico, o que também deve ser levado em consideração. Logicamente, esses aspectos não deveriam ser vinculados à condicionalidade em si, mas às condições geradas pelo PBF, tendo em vista a obrigatoriedade da educação. Todavia, não se pode negar que a condicionalidade acabou afetando diretamente a permanência de milhares de crianças e jovens na escola.

A despeito dessas constatações apresentadas em favor do PBF quanto a seus efeitos na área da educação, é necessário alertar para a existência de análises 
contrárias em relação ao programa em si. Lavinas (2007, p. 1470) acredita que o PBF possa solucionar a volatilidade da renda e do emprego, bem como a vulnerabilidade dos mais pobres, revela equívocos na compreensão do que é pobreza e de seu processo de reprodução: "o Bolsa Família deve se transformar em um direito, estendido a todas as crianças, independentemente de sua classe social e nível de renda, já que, nos lembra a teoria econômica, a presença de crianças é um indicador 'automático' de vulnerabilidade". A autora defende a instituição de uma renda básica universal incondicional.

Também cabe destacar estudos que consideram outros aspectos relacionados ao desempenho escolar que vão além da influência da renda na trajetória escolar. Citamos o trabalho de Barbosa e Randall (2004), autoras que destacam estudos que analisam fatores socioculturais, como a educação dos pais, o capital de relações sociais da família e a estrutura familiar, considerados mais relevantes que o seu capital econômico, quando se trata da definição da trajetória escolar dos estudantes. No texto aqui citado, elas incluem as expectativas familiares sobre o destino escolar de suas crianças como um desses fatores socioculturais, bem como tratam da expectativa de professoras sobre seus alunos. No que diz respeito à renda familiar, concluem que é um fator muito forte na formação das expectativas das mães que participaram do estudo. No entanto, reforçam que o elemento sociocultural "escolaridade da mãe" ainda é mais forte, ou seja, quanto maior a escolaridade da mãe, maior a expectativa em relação à trajetória escolar dos filhos. No que diz respeito às professoras, o aspecto renda não influencia, segundo o estudo, na formação das expectativas ou das opiniões delas sobre a trajetória escolar dos alunos. Há, nesse caso, um domínio substancial do desempenho objetivo dos estudantes.

Conforme Yannoulas (2013a), na relação educação-pobreza, a segunda não deve ser vista como problema técnico, mas como elemento que põe em questão a verdadeira possibilidade da universalidade da educação básica, mesmo considerando as perspectivas da realidade social do capital. Da mesma forma, a condição de pobreza questiona as potencialidades do formato escolar nessa ordem social.

A presença de pobres na escola não é nova, ${ }^{4}$ mas sua dimensão ampliou-se e aprofundou-se. Novos atores escolares foram chamados a cumprir tarefas demandadas pela implementação do PBF. Antigos atores escolares tiveram suas tarefas modificadas em razão da incorporação de setores sociais ao universo escolar. Essa realidade ainda carece de pesquisas. Certamente, a educação básica no Brasil mudou nas últimas duas décadas, mas as alterações aconteceram, em grande medida, na educação pública. A educação básica de caráter privado não se viu afetada por essas mudanças no que diz respeito ao público escolar, às tarefas escolares e aos atores docentes.

\footnotetext{
${ }^{4}$ Em 27 de maio de 1836, os alunos de Minas Novas foram submetidos a exame. O juiz de paz escreveu ao governo que os alunos "se mostraram quase todos mais adiantados em doutrina e aritmética que na leitura e escrita". Depois do exame, o juiz procurou saber o motivo da falta de adiantamento em leitura e escrita e foi informado pelo professor que a pobreza de muitos pais e educadores não lhes permitia comprar papel para os meninos, o que dificultava a aprendizagem. (Faria Filho et al., 2012, p. 56).
} 


\section{Considerações finais}

A escola constitui-se no principal referente das famílias pobres, e em algumas localidades é o único referente do poder público. As crianças e jovens são maioria entre os pobres e frequentam a escola pública 200 dias/ano. Entendemos, portanto, que o estudo sobre a relação entre educação, pobreza e desigualdade social não pode ocorrer dissociado das reflexões sobre a multideterminação que a conforma.

Diversos estudos apontam as dificuldades para uma compreensão aprofundada da relação entre a política educacional e a situação de pobreza, considerando essa relação multideterminada (Yannoulas; Assis; Monteiro, 2012). A escola pública tornou-se um espaço importante de reflexão a respeito da própria ordem social, seu funcionamento, suas contradições, seus limites. Propostas como a Iniciativa Educação, Pobreza e Desigualdade Social (IEPDS), apresentada pela Secadi/MEC em 2014, são fundamentais para a garantia do "direito do pobre a saber-se", como propõe Arroyo (2015).

Devemos lutar por uma educação universal no sentido dado por Saviani e Duarte (2010). Da mesma forma, devemos continuar lutando pela garantia do direito à educação pública, gratuita e de qualidade para todos, em todos os níveis. Também não podemos discordar da necessidade de se rever a condicionalidade aqui tratada, visto que a educação, para além de um direito, já se constitui em uma obrigação. Nesse contexto, não podemos discordar que condicionar o direito ao acesso a condições básicas de vida seja um grande problema.

Essa educação qualificada à qual nos referimos implica um trabalho multidisciplinar, multiprofissional e intersetorial. Nesse sentido, há que se rever a forma como a escola pública está organizada, o papel que tem cumprido. É necessário repensar o currículo, estabelecer relações que efetivamente contribuam para que se possa compreender a realidade social em que vivemos. A pobreza constitui essa realidade, portanto, tem de ser discutida no interior da escola pública.

Ao apresentar essa proposição, não entendemos que a universalização da educação e sua obrigatoriedade, mesmo com a garantia da qualidade desejada, possibilitem a erradicação da pobreza. Se a pobreza é, em si, uma medida, uma ordem social de classes não pode erradicá-la, visto que a desigualdade social sempre colocará uma parcela da população nessa condição, independentemente do parâmetro adotado. Contudo, é fundamental que se exija aquilo que a própria ordem social, com base em seu corolário legal e político, diz ser capaz de realizar. Essa é a forma de confrontar essa ordem. 


\section{Referências bibliográficas}

ARROYO, M. G. Pobreza e currículo: uma complexa articulação. Brasília: MEC, 2015. (Educação, Pobreza e Desigualdade Social, IV). Disponível em: < http://egpbf.mec.gov.br/modulos/pdf/modulo4.pdf > . Acesso em: 7 fev. 2017.

BARBOSA, M. L. O.; RANDALL, L. Desigualdades sociais e a formação de expectativas familiares e de professores. Caderno CRH, Salvador, v. 17, n. 41, p. 299-308, maio/ago. 2004. Disponível em: < https://portalseer.ufba.br/index. php/crh/article/view/18496/11872>. Acesso em: 13 jul. 2017.

BRASIL. Decreto no 591, de 6 de julho de 1992. Atos internacionais. Pacto Internacional sobre Direitos Econômicos, Sociais e Culturais. Promulgação. Disponível em: < http://www.planalto.gov.br/ccivil_03/decreto/1990-1994/d0591.htm>.

BRASIL. Lei no 13.005, de 25 de junho de 2014. Aprova o Plano Nacional de Educação - PNE e dá outras providências. Disponível em: < http://www.planalto. gov.br/ccivil_03/_ato2011-2014/2014/lei/113005.htm>. Acesso em: 3 fev. 2017.

BRASIL. Ministério da Educação (MEC). Secretaria de Educação Continuada, Alfabetização, Diversidade e Inclusão (Secadi). Acompanhamento da condicionalidade da educação do programa Bolsa Família: avanços, desafios e perspectivas: gestão 2011-2014. Brasília: MEC, 2014.

\section{COMISSÃO ECONÔMICA PARA A AMÉRICA LATINA E O CARIBE (Cepal).} Panorama Social da América Latina. Santiago do Chile, 2014. Disponível em: <http://repositorio.cepal.org/bitstream/handle/11362/37706/1/S1420848_ pt.pdf $>$. Acesso em: 2 fev. 2017.

CURY, C. R. J.; FERREIRA, L. A. M. Obrigatoriedade da educação das crianças e adolescentes: uma questão de oferta ou de efetivo atendimento? Nuances: Estudos sobre Educação, Presidente Prudente, v. 17, n. 18, p. 124-145, jan./dez. 2010. Disponível em: < http://revista.fct.unesp.br/index.php/Nuances/article/ viewFile/729/741>. Acesso em: 29 dez. 2016.

DUARTE, N. S. Política social: um estudo sobre educação e pobreza. 2012. 259 p. Tese (Doutorado em Política Social) - Instituto de Ciências Humanas, Universidade de Brasília, Brasília, 2012. Disponível em: < http://repositorio.unb. br/bitstream/10482/10909/1/2012 NataliadeSouzaDuarte.pdf > . Acesso em: 27 out. 2016

DURKHEIM, É. Educação e sociologia. Petrópolis: Vozes, 2011.

ENGELBRECHT, H. Geschichte des österreichischen Bildungswesens. Wien, 1984.

FARIA FILHO, L. M. et al. (Org.) Reformas educacionais no Brasil: democratização e qualidade da escola pública. Belo Horizonte: Maza, 2010.

FERREIRA JR., A.; BITTAR, M. Educação na perspectiva marxista: uma abordagem baseada em Marx e Gramsci. Interface: Comunicação, Saúde, Educação, Botucatu, v. 12, n. 26, p. 635-646, jul./set. 2008. Disponível em: < http://www.scielo.br/pdf/ icse/v12n26/a14.pdf>. Acesso em: 29 dez. 2016. 
FREITAG, B. Escola, Estado e sociedade. 5. ed. São Paulo: Moraes, 1984.

GARCIA, A. V. A pobreza humana: concepções, causas e soluções.

Florianópolis: Em Debate, 2012. Disponível em: < http://docs11.minhateca. com.br/856258699,BR,0,0, Adir-Valdemar-Garcia---A-Pobreza-HumanaConcep\%C3\%A7\%C3\%B5es,-Causas-e-Solu\%C3\%A7\%C3\%B5es.pdf>. Acesso em: 18 jan. 2017.

GARCIA, A. V.; TUMOLO, P. Pobreza: reflexões acerca do fenômeno. Revista da Abet, Recife, v. 8, n. 1, p. 111-124, 2009. Disponível em: <http://periodicos. ufpb.br/ojs/index.php/abet/article/view/15261/8667>. Acesso em: 18 jan. 2017.

GROPPO, L. A. A modernidade e a sociologia da educação no século XX: a questão da racionalidade e da emancipação na reflexão sociológica sobre a educação em Durkheim, Mannheim e Adorno. In: JORNADA DO HISTEDBR, 7., 2007, Campo Grande. Anais... Campo Grande: UNIDERP, 2007. p. 1-25. Disponível em: <http://www.histedbr.fe.unicamp.br/acer_histedbr/jornada/jornada7/_ GT1\%20PDF/A\%2OMODERNIDADE\%20E\%20A\%20SOCIOLOGIA\%20DA\%20 EDUCA\%C7\%C3O\%20NO\%20S\%C9CULO\%20XX\%20A.pdf>. Acesso em: 29 dez. 2016.

HORTA, J. S. B. Direito à educação e obrigatoriedade escolar. Cadernos de Pesquisa, São Paulo, n. 104, p. 5-34, jul. 1998. Disponível em:

$<$ http://publicacoes.fcc.org.br/ojs/index.php/cp/article/view/713>. Acesso em: 29 dez. 2016.

INSTITUTO DE PESQUISA ECONÔMICA APLICADA (Ipea). Número de indivíduos extremamente pobres: linha de pobreza baseada em necessidades calóricas. 2017a. Disponível em: < http://www.ipeadata.gov.br/Default.aspx>. Acesso em: 3 fev. 2017.

INSTITUTO DE PESQUISA ECONÔMICA APLICADA (Ipea). Número de indivíduos pobres: linha de pobreza baseada em necessidades calóricas. 2017b. Disponível em: <http://www.ipeadata.gov.br/Default.aspx>. Acesso em: 3 fev. 2017.

KLEIN, R. Como está a educação no Brasil? O que fazer? Ensaio: Avaliação e Políticas Públicas em Educação, Rio de Janeiro, v. 14, n. 51, p. 139-172, abr./ jun. 2006. Disponível em: < http://www.scielo.br/pdf/ensaio/v14n51/a02v1451>. Acesso em: 13 jul. 2017.

LAVINAS, L. Gasto social no Brasil: programas de transferência de renda versus investimento social. Ciência \& Saúde Coletiva, Rio de Janeiro, v. 12, n. 6, p. 14631476, dez. 2007. Disponível em: < http://www.scielo.br/pdf/csc/v12n6/v12n6a07.pdf> . Acesso em: 13 jun. 2017.

MARX, K.; ENGELS, F. Manifesto do Partido Comunista. São Paulo: Martin Claret, 2002.

MARX, K.; ENGELS, F. Textos sobre educação e ensino. Campinas: Navegando, 2011. Disponível em: < https://www.marxists.org/portugues/marx/ano/mes/ ensino.pdf>. Acesso em: 13 jul. 2017. 
MÉSZÁROS, I. Filosofia, ideologia e ciência social: ensaios de negação e afirmação. São Paulo: Ensaio, 1993.

NOVELLI, P. G. A. A universalidade da educação em Hegel. Dialectus, Fortaleza, v. 1, n. 1, p. 179-191, jun./dez. 2012. Disponível em:

< http://www.revistadialectus.ufc.br/index.php/RevistaDialectus/article/ view/26/30>. Acesso em: 22 dez. 2016.

O'BRIEN, G. Maria Theresa's attempt to educate an Empire. Paedagogica Historica, v.10, n.3, p.542-565, 1970.

OXFAM. Gobernar para las elites: secuestro democrático y desigualdade económica. 2014. Disponível em: <http://www.oxfamintermon.org/es/ documentos/17/01/14/gobernar-para-elites-secuestro-democratico-desigualdadeconomica >. Acesso em: 22 dez. 2016.

PEREIRA, P. A. P.; STEIN, R. H. Política social: universalidade versus focalização: um olhar sobre a América Latina. In: BOSCHETTI, I. et al. (Org.). Capitalismo em crise, política social e direitos. São Paulo: Cortez, 2010. p. 106-130.

PIRES, A. Efeitos da condicionalidade em educação do programa Bolsa Família em Campinas (SP). Estudos em Avaliação Educacional, São Paulo, v. 24, n. 55, p. 170196, abr./ago. 2013. Disponível em: < http://www.fcc.org.br/pesquisa/publicacoes/ eae/arquivos/1817/1817.pdf> . Acesso em: 3 fev. 2017.

RAMOS, C. A. A crítica marxista do Estado hegeliano. Revista de Sociologia e Política, Curitiba, n. 1, p. 57-64, 1993. Disponível em: < revistas.ufpr.br/rsp/ article/download/39395/242010>. Acesso em: 29 dez. 2016

RIBEIRO, S. C. A pedagogia da repetência. Estudos Avançados, São Paulo, v. 5, n. 12, p. 7-21, maio/ago. 1991. Disponível em: <http://www.scielo.br/pdf/ea/ v5n12/v5n12a02.pdf>. Acesso em: 13 jun. 2017.

SAVIANI, D. Contribuições da filosofia para a educação. Em Aberto, Brasília, v. 9, n. 45, p. 3-9, jan./mar. 1990. Disponível em: < rbep.inep.gov.br/index.php/ emaberto/article/download/1762/1733 >. Acesso em: 29 dez. 2016.

SAVIANI, D.; DUARTE, N. A formação humana na perspectiva históricoontológica. Revista Brasileira de Educação, Rio de Janeiro, v. 15, n. 45, p. 422433, set./dez. 2010. Disponível em: < http://www.scielo.br/pdf/rbedu/v15n45/02> . Acesso em: 29 dez. 2016.

SEVERINO, A. J. A busca do sentido da formação humana: tarefa da filosofia da educação. Educação e Pesquisa, São Paulo, v.32, n.3, p. 619-634, set./dez. 2006. Disponível em: < http://www.scielo.br/scielo.php?script=sci_arttext\&pid =S1517-97022006000300013 >. Acesso em: 29 dez. 2016.

SIMÕES, A. Pesquisador avalia impactos do Bolsa Família na aprendizagem dos alunos. Entrevista publicada no Portal Brasil em 28 out. 2013. Disponível em: < http://www.brasil.gov.br/cidadania-e-justica/2013/10/efeitos-de-longo-prazoentrevista-publicada-na-carta-na-escola > . Acesso em: 16 fev. 2017. 
TELES, A.; STEIN, R. H. Programas de transferência de renda e condicionalidades educacionais: acesso ao direito ou moralização do acesso? In: YANNOULAS, S. C. (Coord.). Política educacional e pobreza: múltiplas abordagens para uma relação multideterminada. Brasília: Liber Livro, 2013. p. 193-211. Disponível em: <http://www.tedis.unb.br/images/pdf/Obeduc_RelatorioFinalAtividades2013_ Anexo12_Livro.pdf>. Acesso em: 26 jul. 2016.

YANNOULAS, S. C. Acerca de como las mujeres llegaron a ser maestras (America Latina, 1870-1930). Revista Brasileira de Estudos Pedagógicos, Brasília, v. 73, n. 175, p. 497-521, set./dez. 1992. Disponível em: <http://rbep.inep.gov.br/index. php/rbep/article/viewFile/1236/1210> . Acesso em: 18 jan. 2017.

YANNOULAS, S. C. Apresentação. In: YANNOULAS, S. C. (Coord.). Política educacional e pobreza: múltiplas abordagens para uma relação multideterminada. Brasília: Liber Livro, 2013a. p. 11-25. Disponível em: < http://www.tedis.unb.br/ images/pdf/Obeduc_RelatorioFinalAtividades2013_Anexo12_Livro.pdf $>$. Acesso em: 16 jan. 2017.

YANNOULAS, S. C. Literatura recente sobre uma antiga problemática. In: YANNOULAS, S. C. (Coord.). Política educacional e pobreza: múltiplas abordagens para uma relação multideterminada. Brasília: Liber Livro, 2013b. p. 25-65. Disponível em: < http://www.tedis.unb.br/images/pdf/Obeduc_ RelatorioFinalAtividades2013_Anexo12_Livro.pdf>. Acesso em: 16 jan. 2017.

YANNOULAS, S. C.; ASSIS, S. G.; MONTEIRO, K. F. Educação e pobreza: limiares de um campo em (re)definição. Revista Brasileira de Educação, Rio de Janeiro, v. 17, n. 50, p. 329-351, 2012. Disponível em: < http://www.scielo.br/pdf/rbedu/ v17n50/v17n50a05.pdf>. Acesso em: 16 jan. 2017.

ZIMMERMANN, C. R. Os programas sociais sob a ótica dos direitos humanos: o caso do Bolsa Família do governo Lula no Brasil. SUR: Revista Internacional de Direitos Humanos, São Paulo, v. 3, n. 4, p.144-159, 2006. Disponível em: <http://www.scielo.br/pdf/sur/v3n4/08.pdf>. Acesso em: 29 dez. 2016.

Adir Valdemar Garcia, doutor em Sociologia Política pela Universidade Federal de Santa Catarina (UFSC), é professor adjunto do Centro de Ciências da Educação dessa universidade.

adirvg@yahoo.com.br

Silvia Cristina Yannoulas, doutora em Sociologia da América Latina e Caribe pelo Programa de Doutorado Conjunto Flacso/Brasil e Universidade de Brasília (UnB) e pós-doutora pela Faculdade de Educação da Universidade Federal de Minas Gerais (FAE/UFMG), é professora do Departamento de Serviço Social e do Programa de Pós-Graduação em Política Social da UnB. Lidera o Grupo de Pesquisa Trabalho, Educação e Discriminação (TEDis/SER/UnB) e participa dos grupos Politiza/SER/UnB e Gestrado/FAE/UFMG. Integra o Conselho Assessor do Programa Regional de Formação em Gênero e Políticas Públicas (Prigepp) da Flacso/Argentina.

silviayannoulas@unb.br 